\title{
An Audit on Near-Miss Events in Transfusion Medicine: The Experience of the Teaching Hospital in Northeastern Malaysia
}

\author{
M. N. Noor Haslina, M. Y. Shafini, B. Rosnah, R. Marini, \\ S. Salamah, and M. A. Mohd Fakhri \\ Transfusion Medicine Unit, Hospital Universiti Sains Malaysia, 16150 Kubang Kerian, Kelantan, Malaysia \\ Correspondence should be addressed to M. N. Noor Haslina, drhaslina@kb.usm.my
}

Received 4 July 2010; Revised 27 October 2010; Accepted 29 December 2010

Academic Editor: Silvano Wendel

Copyright ( $) 2011$ M. N. Noor Haslina et al. This is an open access article distributed under the Creative Commons Attribution License, which permits unrestricted use, distribution, and reproduction in any medium, provided the original work is properly cited.

\begin{abstract}
The rate of near misses in transfusion is important as it indicates situations with the potential of adverse outcome. The aim of this study was to assess the frequency of mislabeled and miscollected samples received by our transfusion medicine unit. This study was conducted from January to December 2009 in Transfusion Medicine Unit, Hospital Universiti Sains Malaysia. The total number of near-miss events reported and analysed over the 1-year period was $178(0.40 \%)$. All mislabeled and miscollected samples and its location cases were identified. Mislabeled and miscollected (WBIT) samples were $66.3 \%$ and $33.7 \%$, respectively. The highest number of mislabeled and miscollected samples was from accident and emergency unit and medical ward, respectively. Continuous monitoring and analysis of near misses data should be mandatory in order to improve the safety of transfusion.
\end{abstract}

\section{Introduction}

Hospital Universiti Sains Malaysia is a teaching hospital in northeastern Malaysia with a total of 800 beds. The services that are offered by the transfusion medicine laboratory range from routine immunohematology, that is, $\mathrm{ABO}$ and Rh grouping, group screen and hold, group cross match, antibody titre and direct Coombs test, to special tests that is, red cell antibody identification, platelet antibody screening, cold agglutinin test, Donath Leinsteiner test, and so forth. We also provide peripheral stem cell collection and preparation for the haemato-oncology unit in the hospital. The laboratory is run by 6 medical technologists, 3 senior medical technologists, 1 scientific officer, and 2 haematologists.

Most errors result from human actions. Hence, the errors may be preventable, and hospital-wide efforts at prevention are required [1]. Safety and reliability in blood transfusion are not static are dynamic nonevents. Collection of the patient's sample for pretransfusion testing initiates a complex chain of events in the transfusion process [2].

Half of the reported serious adverse events from transfusion are consequences of medical errors. The greatest risk in transfusion medicine is actually human error, resulting in the use of the incorrect blood component [3].

Mislabeled sample is defined as that not meeting local standards for sample acceptance. Miscollected sample is defined as sample in which the ABO or D type of the blood in the tube is different from the result already in the record for the patient's name on the tube with the exception of change in blood type due to bone marrow transplantation [4].

A major cause of ABO-incompatible transfusion is the "wrong blood in tube" (WBIT) phenomenon, that is, the sample is not from the recipient identified on the label [5]. An audit of mislabeled and miscollected samples should be carried out to identify the causes of errors, and the conclusions should be reported to the institution staffs for the prevention of similar errors [3].

This study was done to identify the rate of near-misses in our laboratory as an effective mean of highlighting human and system failure associated with transfusion.

\section{Materials and Methods}

This prospective study was conducted from January to December 2009 in Transfusion Medicine Unit, Hospital 
Universiti Sains Malaysia. All the blood samples were taken by the medical officer or house officer at the respective wards as we did not have specific phlebotomy staff. The samples should be labeled clearly and should include patient's full name, registration number or identity card number, date and time of collection, and the initial/signature of the person who was taking the blood. Failure to comply with the above requirements resulted in sample rejection. The sample would also be rejected if the request form was inadequately filled up or there were discrepancies between the information on the sample label and the request form.

Mislabeled sample was defined as the sample that did not fulfill the above criteria for acceptance by the laboratory. Miscollected sample was also called wrong blood in tube (WBIT) or defined as samples in which the blood group result was different from the result on the file from the prior testing. All mislabeled and miscollected cases were included as near-miss events.

Samples which were properly labeled but were not acceptable to the laboratory for other reasons (i.e., insufficient volume of blood in the tube or presence of haemolysis) were not included.

All staffs in our immunohaematology laboratory could report events that were considered near-miss errors.

Locations with a high proportion of mislabeled and miscollected samples were identified every month.

\section{Results}

The number of samples submitted to the transfusion laboratory in 2009 was 44194.

The total number of near-miss events reported and analysed over the 1 -year period was $178(0.4 \%)$. Mislabeled samples were 66.3\% (118/178) (wrong registration number, wrong name, and others, that is, incomplete form/discrepancies between sample labels and forms were 39, 52 and 29 cases resp.) and miscollected (WBIT) samples were 33.7\% (60/178) cases (Table 1). The mean reporting rate was 15 events per month. During the same period, 33958 blood components were issued by our transfusion medicine unit, corresponding to a reporting rate of five near-miss events per 1000 units issued. Frequency of events and samples received was shown in Table 2.

The highest number of mislabeled samples was from accident and emergency unit whereas the highest number of miscollected samples was from medical ward. All the mislabeled and miscollected samples were detected by the laboratory staffs during the pretransfusion testings.

\section{Discussion}

Errors in the collection and labeling of patient sample for pretransfusion testing are known to be an important source of transfusion-related patient morbidity and mortality [4]. Near-miss events are five times more frequent than actual transfusion errors, and the majority of errors are detected before the blood was issued [5]. A study by Ibojie and
Urbaniak showed that $75 \%$ of transfusion errors were detected as near-misses [6].

We reported that total near-miss cases encountered by our transfusion medicine laboratory for the year of 2009 was 178 cases $(0.4 \%)$. It was observed that the frequency of mislabeled samples was higher than miscollected samples which were $6.3 \%$ and $33.7 \%$, respectively. These findings were supported by Gonzalez-Porras et al. who reported that the frequency of inappropriately labeled samples was higher than those of miscollected samples and wrong blood in tube (WBIT) which were $6.45 \%$ and $0.06 \%$, respectively [3].

We observed that the rate for mislabeled samples was 1 in every 374 samples, and 1 in 736 samples for the miscollected samples which was higher than reported by Dzik et al. A study on the performance of sample collection in 71 hospitals from 10 different nations showed that the median hospital performance resulted in a rate for mislabeling of 1 in every 165 samples. There was a very low rate of miscollected samples in Sweden and Finland. However, outside these nations, miscollected samples occurred at a median rate of 1 in every 1986 samples [7].

We observed that the emergency department and medical wards contributed to the high rate of near-miss events that were mislabeled and miscollected samples. These results were supported by Lundy et al. who reported that other than the general ward areas where the majority of transfusion activity took place, the accident and emergency (A \& E) department and the transfusion laboratory were the two departments where significant numbers of near-miss events occurred [8].

Sample collection is the step in the work process where the majority of events first occurred. Prescription/request is also highlighted as a potentially high-risk step in the work process which contributes to the near-miss events [8]. In our hospital, mislabeled and miscollected samples were discovered during crosschecking of sample information on the request forms and sample tubes before the pretransfusion testings. We found that all the mislabeled occurred in the ward during the labeling process where blood was taken from the intended patients but was wrongly labeled either in the name or registration number. We observed that all of the miscollected samples were associated with phlebotomy where blood was taken from other patients and labeled for the intended patients. Our findings were supported by Ibojie and Urbaniak who observed that almost half of the nearmisses were due to problems with patient identification at phlebotomy [6]. The majority of events were reported to occur outside the blood bank and effort of prevention is required [1].

Near-miss events were discovered at the sample-handling step in the laboratory during crosschecking of the details on the request forms and sample tubes and after the product were issued, which were $53 \%$ and $24 \%$, respectively. In $33 \%$ of these events, the discovery was made by chance [8].

Near-miss events also occurred at some point after issue from the laboratory but before administration; these included events in which the wrong unit was collected from the site of storage [8].

Way of labeling also contributes to near-miss events where it is reported that preprinted label gives higher rate of 
TABLE 1: Reported events: breakdown of reporting types and rates per units transfused.

\begin{tabular}{lcccc}
\hline $\begin{array}{l}\text { Near-miss events reported } \\
\text { over 12 months }\end{array}$ & Mislabeled & Miscollected & $\begin{array}{l}\text { Units transfused } \\
\text { over 12 months }\end{array}$ & $\begin{array}{l}\text { Near-miss events per } \\
1000 \text { units transfused }\end{array}$ \\
\hline 178 & 118 & 60 & 33958 & 5.2 \\
\hline
\end{tabular}

TABLE 2: Frequency of events and samples received.

\begin{tabular}{lcc}
\hline $\begin{array}{l}\text { Total samples } \\
\text { received }\end{array}$ & $\begin{array}{c}\text { Frequency of } \\
\text { mislabeled }\end{array}$ & $\begin{array}{c}\text { Frequency of } \\
\text { miscollected }\end{array}$ \\
\hline 44194 & $\begin{array}{c}1 \text { in every } 374 \\
\text { samples }\end{array}$ & $\begin{array}{c}1 \text { in every } 736 \\
\text { samples }\end{array}$ \\
\hline
\end{tabular}

error in transfusion medicine compared to handwritten label [3].

Failing to check patient identification at the bedside and remote labeling of samples in areas such as the nurse's station have demonstrated a clear correlation with high risk events [8].

Medical staffs are most frequently involved in error. Errors involving doctors are related to errors associated with sample collection. Nursing staff, laboratory staff, phlebotomy staff, clerical staff, and "other" grades of staff are also observed to involve in the near-miss events [8].

Clinical staffs were reported to give a higher rate of inappropriate labeled compared to that of blood bank staff which was $8.8 \%$ and $2.1 \%$, respectively [3]. Most errors observed result from human actions and should be preventable [1].

Ongoing monitoring and analysis of labeling and collection should be mandatory in order to improve the safety of transfusion [3]. Baseline performance data may be useful in formulating national standards of performance for sample collection from patients [7]. Hospitals can monitor the performance of the sample collection process by doing periodic analysis of mislabeled and miscollected samples [7]. Statistical process control (SPC) techniques are formal methods for monitoring process over time. It is used to document a critical process that is in control and to alert responsible parties when a process wanders out of control. It is a useful tool to assess the effect of new interventions intended to improve blood transfusion therapy [4]

It is reported that difficulty in gaining access to medical staff for transfusion or haemovigilance training is one of the major obstacles in establishing best practice and compliance [8]. Phlebotomy training for nurses working in the A \& E department is important to improve the phlebotomy service [8]. It is observed that the percentage of inappropriately labeled samples has decreased with educational intervention, and hand-written labels represent the best method of labeling compared to preprinted labels [3].

The use of barcode patient identification has shown significant improvement in the procedure for the administration of blood. Previous study has evaluated a barcode patient identification system involving hand-held computers for blood sample collection for compatibility testing and administration of blood. The study found that it was easy to operate and prevented staff from becoming distracted and interrupted during the process of transfusion therapy [9]. This was supported by another study that barcodes identification technology was being implemented in order to improve performance sample labeling and the bedside check [10].

The rate of mislabeled and miscollected samples (WBIT) can be used to track the performance of sample collection [7].

\section{Conclusions}

Most near-miss events result from human actions and thus may be preventable. The majority of events occur outside the blood bank, and the bedside of the patient is the main location. Education of the staff responsible for transfusion to comply with the existing guidelines is a key step towards improving performance.

\section{References}

[1] J. V. Linden, K. Wagner, A. E. Voytovich, and J. Sheehan, "Transfusion errors in New York State: an analysis of 10 years' experience," Transfusion, vol. 40, no. 10, pp. 1207-1213, 2000.

[2] M. F. Murphy, B. E. Stearn, and W. H. Dzik, "Current performance of patient sample collection in the UK," Transfusion Medicine, vol. 14, no. 2, pp. 113-121, 2004.

[3] J. R. Gonzalez-Porras, I. F. Graciani, M. Alvarez et al., "Tubes for pretransfusion testing should be collected by blood bank staff and hand labelled until the implementation of new technology for improved sample labelling. Results of a prospective study," Vox Sanguinis, vol. 95, no. 1, pp. 52-56, 2008.

[4] W. S. Dzik, N. Beckman, K. Selleng et al., "Errors in patient specimen collection: application of statistical process control," Transfusion, vol. 48, no. 10, pp. 2143-2151, 2008.

[5] D. MacIvor, D. J. Triulzi, and M. H. Yazer, "Enhanced detection of blood bank sample collection errors with a centralized patient database," Transfusion, vol. 49, no. 1, pp. 40-43, 2009.

[6] J. Ibojie and S. J. Urbaniak, "Comparing near misses with actual mistransfusion events: a more accurate reflection of transfusion errors," British Journal of Haematology, vol. 108, no. 2, pp. 458-460, 2000.

[7] W. H. Dzik, M. F. Murphy, G. Andreu et al., "An international study of the performance of sample collection from patients," Vox Sanguinis, vol. 85, no. 1, pp. 40-47, 2003.

[8] D. Lundy, S. Laspina, H. Kaplan, B. Rabin Fastman, and E. Lawlor, "Seven hundred and fifty-nine (759) chances to learn: a 3-year pilot project to analyse transfusion-related near-miss events in the Republic of Ireland," Vox Sanguinis, vol. 92, no. 3, pp. 233-241, 2007. 
[9] M. F. Murphy and J. D. S. Kay, "Barcode identification for transfusion safety," Current Opinion in Hematology, vol. 11, no. 5, pp. 334-338, 2004.

[10] W. H. Dzik, "New technology for transfusion safety," British Journal of Haematology, vol. 136, no. 2, pp. 181-190, 2007. 


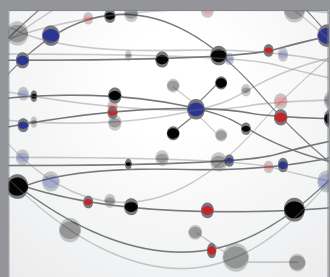

The Scientific World Journal
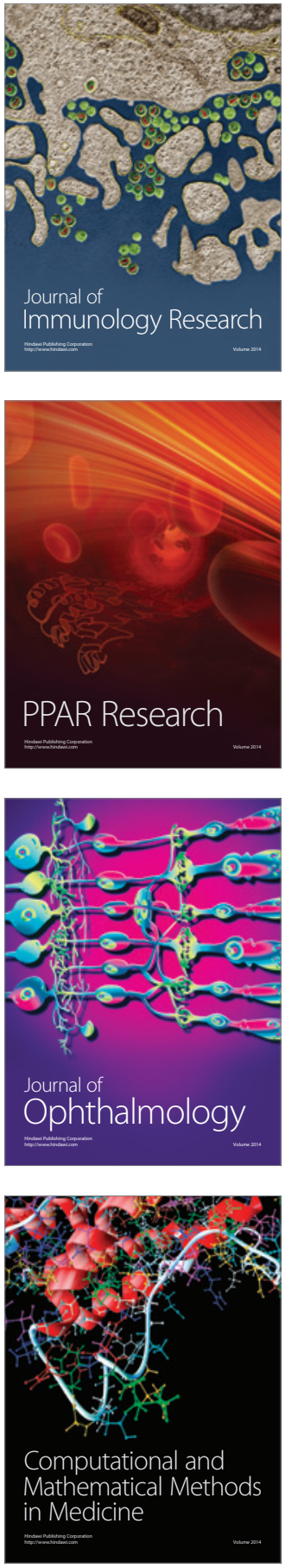



Gastroenterology

Research and Practice


\section{Hindawi}

Submit your manuscripts at

http://www.hindawi.com
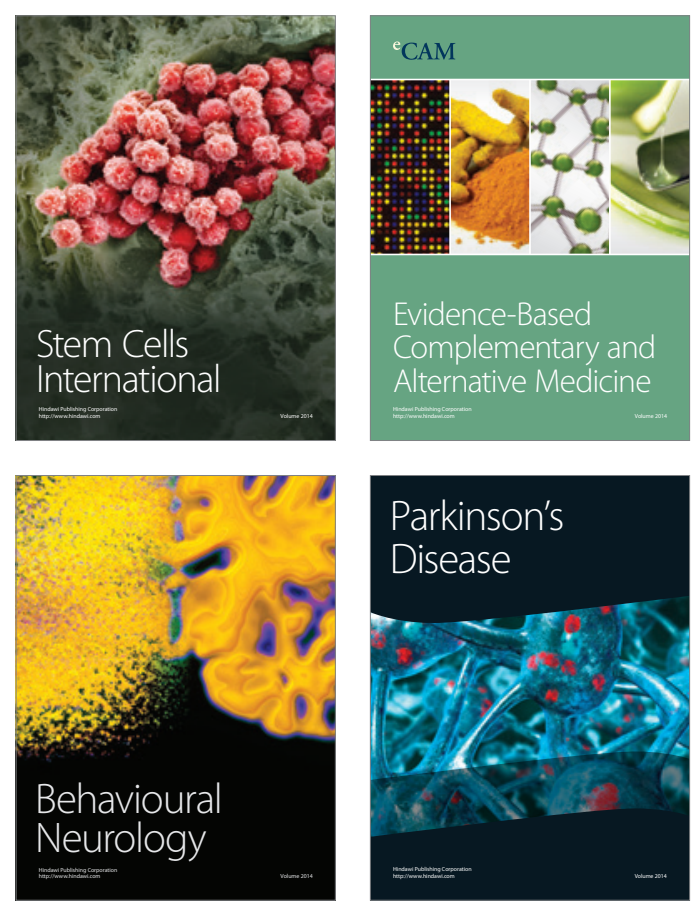

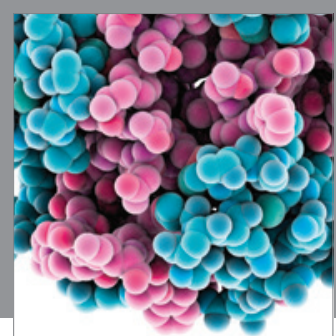

Journal of
Diabetes Research

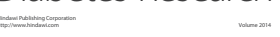

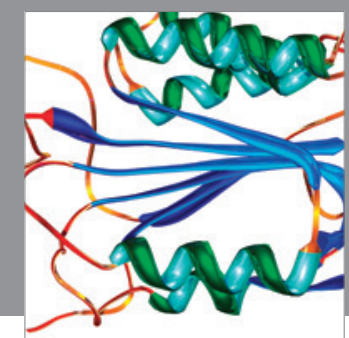

Disease Markers
